\title{
Depressive and anxiety symptoms in patients with Metabolic Syndrome
}

\author{
Sintomas de depressão e de ansiedade em \\ pacientes com Síndrome Metabólica
}

\author{
Lilian Lopes SHAROVSKY ${ }^{1}$ \\ Bellkiss Wilma ROMANO
}

\begin{abstract}
Depressive symptoms have been associated to the Metabolic Syndrome. Nevertheless, only a few studies have evaluated anxiety and depression concomitantly. The objective of the research was to evaluate the intensity of depressive and anxiety symptoms in patients with Metabolic Syndrome and their relation to demographic variables. A unicenter, transversal study was carried out. A social demographic questionnaire was used. Depressive symptoms were measured with Beck Depression Inventory and anxiety symptoms were measured with Hamilton Anxiety Scale Rate. A total of 103 ambulatory patients, 60 of them men, with mean age 55.4 years $( \pm 7,6)$ with a diagnosis of Metabolic Syndrome were included in the study. Anxiety symptoms of very severe intensity were present in $51.5 \%(n=53)$ while severe depressive symptoms in only $5.8 \%(n=6)$. Anxiety and depressive symptoms were significantly associated. In this sample, anxiety predominated in relation to the depressive symptoms. The anxiety symptoms were more intense in women and that had low level of education.
\end{abstract}

Uniterms: Anxiety; Depression; Metabolic syndrome.

\section{Resumo}

Os sintomas depressivos têm sido associados à Síndrome Metabólica. No entanto, poucos estudos avaliam simultaneamente ansiedade e depressão nessa população. A pesquisa teve por objetivo avaliar a intensidade de sintomas depressivos e de ansiedade em pacientes com Síndrome Metabólica, correlacionando-a com variáveis sociodemográficas. Configurou um estudo transversal e unicêntrico. Utilizou-se questionário sociodemográfico, Inventário de Depressão de Beck e Escala de Ansiedade de Hamilton. Participaram 103 pacientes ambulatoriais que apresentaram critérios médicos para a Síndrome Metabólica, selecionados consecutivamente. A idade média foi de 55,37 anos ( $\pm 7,62)$, sendo 60 homens. Os sintomas de ansiedade de gravíssima intensidade estiveram presentes em $51,5 \%$ pacientes $(n=53)$, enquanto os sintomas depressivos graves estiveram presentes em 5,8\% (n=6). Houve correlação positiva e expressiva entre as escalas de depressão e de ansiedade. Concluiu-se que, nesta amostra, os sintomas ansiosos de intensidade grave foram predominantes em relação aos sintomas depressivos, sobretudo entre as mulheres e entre indivíduos com baixa escolaridade.

Unitermos: Ansiedade; Depressão; Síndrome metabólica.

\section{$\boldsymbol{\nabla} \mathbf{v} \boldsymbol{\nabla}$}

1 Universidade de São Paulo, Faculdade de Medicina, Instituto do Coração do Hospital das Clínicas. Av. Dr Enéas de Carvalho Aguiar, 65, Consolação, 05403-000, São Paulo, SP, Brasil. Correspondência para/Correspondence to: L.L. SHAROVSKY. E-mail: <liliansharovsky@hotmail.com>.

Article based on the dissertation of the L.L. SHAROVSKY, intitled "Avaliação de Sintomas depressivos e ansiosos nas variáveis clínicas da Síndrome Metabólica". Universidade de São Paulo, 2010.

Support: Fundação de Amparo à Pesquisa do Estado de São Paulo (Process nº 08/58088). 
Metabolic Syndrome (MS) can be defined as a group of cardiovascular risk factors, which includes the presence of at least three of the following diagnosis criteria: abdominal obesity, low High Density Lipoproteins (HDL) cholesterol, high blood pressure, elevated triglycerides and glucose fasting, according to the diagnosis criteria defined by the National Cholesterol Education Program Revised (Summary of the Third Report NCEP-ATP III, 2001). Its etiology is associated with the complex interaction of genetic and environmental factors (Corella \& Ordovas, 2004; Grundy et al., 2005).

There are no representative studies on the prevalence of MS in our population (Sociedade Brasileira de Hipertensão, 2004). In the U.S. adult population, the prevalence of MS is estimated at $23.7 \%$, increasing the risk of significant clinical events (Ford, Giles \& Dietz, 2002).

In turn, symptoms of depression and anxiety symptoms have been associated with the onset of various medical conditions and adverse clinical responses, including cardiovascular disease, and its subsequent morbidity (Blumenthal et al., 2003; Grigsby, Andreson, Freealand, Clouse \& Lustman, 2002; Huffman, Smith, Blais, Januzzi \& Fricchione, 2008).

The First National Consensus and Guidelines for the Treatment of MS, for example, recommends interdisciplinary intervention, with the participation of psychologists, as facilitators of adherence to treatment (Sociedade Brasileira de Hipertensão, 2004). It is known that patients with depressive symptoms and/or anxiety tend to adopt risky behaviors such as overeating, alcohol abuse, physical inactivity, smoking, changes in sleep patterns and non-adherence to medical prescription, which in itself, may contribute to changes in metabolic parameters and worse results in adherence to the therapeutic proposal (DiMatteo, Lepper \& Croghan, 2000).

Several studies, despite having controversial results, have demonstrated an association between depressive symptoms and MS (Björntorp, 2001; Herva et al., 2006; Vaccarino et al., 2008).

Depression and anxiety cases generally share symptoms such as irritability and somatic complaints. Moreover, anxiety symptoms tend to increase the risk of the onset of depression (Van Praag, 2005). However, few studies have measured the intensity of anxious and depressive symptoms simultaneously, correlating the scores (Skilton, Moulin \& Terra, 2007). The present study aimed to determine the intensity of symptoms of depression and anxiety in patients with MS and correlate it to socio-demographic variables.

\section{Method}

This is an observational, cross-sectional study with a sample of 103 patients registered at the Ambulatory the reference hospital in Cardiology in the city of São Paulo (SP). Data was collected between February 6, 2009 and March 31, 2009.

\section{Composition of the sample}

The inclusion criteria were a diagnosis of MS and accepting to take part in the study.

Exclusion criteria were: (1) Congestive heart failure, (2) Chronic Obstructive Pulmonary Disease; (3) Any thyroid disease including subclinical hypothyroidism; (4) History of neoplasia; (5) Use of neuroleptics; (6) Cognitive difficulties to understand the psychological scales, (7) Cerebrovascular Accident.

\section{Data collection}

Patients were consecutively included after accepting the invitation to participate in this study. They were invited on the day of their medical previously scheduled appointments at the Clinic of Lipids, or at the Hypertension Ambulatory or at the Clinic of Nutrition. They were informed about the purpose of the study and their rights as research subjects. Those who agreed to participate read and signed the Terms of consent.

\section{Assessment instruments used}

The following instruments were applied in the following order (1) Demographic questionnaire that included age, gender, years of education, marital status and smoking, and (2) Hamilton Anxiety Rate Scale (HARS) and (3) Beck Depression Inventory (BDI). 
For evaluation of depressive symptoms, the BDI was used, which has been widely applied to individuals who have coexisting medical conditions. It seeks to measure the intensity of depressive symptoms and, therefore, its goal is not to identify nosological categories. According to the rules of the version in Portuguese, in the validation for the target population, the symptoms are classified as: 0-11 (minimum), 12-19 (mild), 20-35 (moderate) and 36-63 (severe) (Cunha, 2001). Although it can be used as a self-report scale, we opted for the application conducted by the same trained investigator, to avoid bias application.

In order to assess the intensity of anxiety symptoms, we used the HARS which is composed of 14 items, seven for evaluating the anxious mood and seven for the evaluation of the somatic sphere associated with anxious symptoms. The intensity of symptoms is classified as: $\leq 17$ (minimum), 18-24 (moderate), 25-30 (severe) and $\geq 30$ very severe (Hamilton 1959). The same professional applying the $\mathrm{BDI}$ also performed the application of HARS.

Throughout the interviews patients identified with significant symptoms of depression and anxiety were referred to the Psychology Service of the institution or to the Basic Health System.

This study was approved by the Research and Ethics Committee of the Heart Institute of Hospital das Clínicas da Faculdade de Medicina da Universidade de São Paulo (HCFMUSP) under 252/03, by Comissão de Ética para Análise de Projetos de Pesquisa (CAPPesq).

We followed the principles of Resolution no 196/ 96 of the National Health Council and the Resolution of the Federal Council of Psychology of 2000 that regulate the conditions of research involving human beings.

\section{Statistical analysis}

The sample size calculation was based on previous studies, observing that approximately $40 \%$ of patients with MS had depressive symptoms. The hypothesis was that, in our sample, the percentage of depression is 40\%, varying between 30\% and 50\%. According to the estimative, with a reliability interval of $95 \%$ we obtained $a n=98$ patients.
The variables were initially analyzed descriptively: frequency distribution, mean, standard deviation median with minimum and maximum values.

Correlations were verified using nonparametric tests. $P$ values were obtained from non-parametric tests, and statistical significance was defined as $p \leq 0.05$ (Type I error).

\section{Results}

\section{Socio-demographic characteristics}

The study included 103 consecutive patients aged between 30 and 70 years (mean 55.4 years), 60 men (58.3\%), who presented the criteria for MS defined by NCEP-ATP III-R. Regarding marital status, 77 participants (74.8\%) of the sample were married or living maritally, while 7 (6.8\%) were widowed, 8 (7.8\%) patients divorced, and the remaining ones, singles. As for education, which was divided in less than 8 years of schooling and over 8 years of study, we obtained, respectively, $n=53$ and $n=51$. From the 103 participants, 85.44\% ( $n=88$ ) reported being nonsmokers, 10 (9.71\%) reported being smokers despite medical guidelines and 5 (4.85\%) declared themselves ex - smokers, having ceased smoke for at least two years.

\section{Depressive symptoms}

The frequency distribution obtained by the Beck Depression Inventory is described in Table 1. It was observed that 76 (73.7\%) of participants obtained scores from minimal to mild severity. There were significant differences regarding gender (Nonparametric MannWhitney Test, $p=0.036)$ : women presented significantly higher values than men in the population studied. Among them, the average was $17.18( \pm 11.51)$, median 14 (minimum 1.00 and maximum 48). Among men, the mean was 12.78 ( \pm 9.62$)$, median of 10.00 being the minimum value of zero and a maximum of 41 . Marital status groups did not differ in relation to the intensity of depressive symptoms (Nonparametric Kruskal-Wallis test, $p=0.833$ ). We observed no significant difference between age and BDI ( $p=0.054)$ nor between BDI and smoking. 
Table 1

Occurrence of depressive symptoms according to BDI

\begin{tabular}{lcc}
\hline BDI & Occurrence & $\%$ \\
\hline Minimum & 50 & 48.5 \\
Mild & 26 & 25.2 \\
Moderate & 21 & 20.4 \\
Severe & 6 & 5.8 \\
\hline
\end{tabular}

Note: BDI: Beck Depression Inventory.

Table 2

Distribution according to HARS

\begin{tabular}{lcc}
\hline HARS & Occurrence & $\%$ \\
\hline Minimum & 22 & 21.4 \\
Moderate & 14 & 13.6 \\
Severe & 14 & 13.6 \\
Very severe & 53 & 51.5 \\
\hline
\end{tabular}

Note: HARS: Hamilton Anxiety Rating Scale.

As for education, no significant difference (Nonparametric Mann-Whitney Test, $p=0.116$ ) among those who had $\geq 8$ years of education ( $n=51$, mean $13.15, \pm 10.06$, median 10, minimum zero and maximum 41 ) and those who had 8 years ( $n=52$, mean 6.05, \pm 11.05 , median 13.50; minimum 0 and maximum 48).

There was a significant positive correlation between BDI and HARS (Spearman correlation coefficient, $p=0.0001$ ).

\section{Anxiety symptoms}

The frequency distribution of the scores obtained by the HARS is described in Table 2, observing that the anxiety symptoms of severe intensity had predominance over the other scores in this sample (51.5\%). As to gender, women had an average of 34.51 ( \pm 11.44 ); median of 34.00 (minimum of 5.00 and maximum of 54.00), while men $(n=60)$ had an average of 25.85 ( \pm 12.99 ), median 25.00 (minimum 6.00 and maximum 56.00). The female group had significantly higher values than men's (Nonparametric Mann-Whitney Test, $p<0.001)$. Regarding age, there was a significant negative correlation the higher the age the lower the value of HARS ( $r=0.275, p=0.005)$. There was significant difference between educational groups: the group with $<8$ years of schooling presents significantly higher value than the group with $\geq 8$ years (Non-parametric MannWhitney Test, $p=0.004$ ). In relation to marital status there was no difference between groups (Kruskal - Wallis test $p=0.088$ ).

\section{Discussion}

There are few national studies on the association between depressive symptoms and anxiety and MS.

It was observed in the present study, greater intensity of depressive symptoms among women than among men. This finding was also obtained with middle-aged patients with MS and measured by the BDI (Koponen, Jokelainnen, Keinänen-Kiukaanniemi, Kumpusalo \& Vanhala, 2007). Other authors, using the reverse approach, found a higher prevalence of MS in women who already had a history of depression (Kinder, Carnethon, Palaviappan, King \& Fortmann, 2004).

However, despite a higher intensity of depressive symptoms among women, that intensity set itself predominantly as mild to moderate, according to the classification proposed for the Brazilian population, which contradicted the initial hypothesis of this study, which expected a more expressive presence of depressive symptoms in the sample with MS studied.

Capuron, Shaoyong, Miller \& Bremner (2008) also found intensity of depressive symptoms from lower to moderate (by the American version of the BDI, which corresponds to the value of $\mathrm{BDI} \geq 14$ ), a value lower than expected by the authors, and only $15 \%$ of the population studied presented moderate to significant symptoms.

Diaz-Martinez et al. (2007) found no significant association between MS and depressive symptoms, as well as Herva et al. (2006), who also found no clear association between depressive symptoms with MS or between MS and anxiety symptoms. These findings are different to those of other authors who found an association between depressive symptoms and MS, regardless of age, sociodemographic and lifestyle, but did not observe the same association with anxiety symptoms (Skilton et al., 2007).

In our study, we obtained positive and significant correlation between the scales of depression and anxiety, even if there was a predominance of more severe anxiety symptoms. The same positive correlation 
was obtained by Arenas et al. (2007), when they studied patients in dialysis programs.

The instruments used (BDI and HARS) to assess the intensity of depressive and anxiety symptoms may help identify patients presenting psychological risk, and by means of psychotherapeutic intervention, contribute to the control of clinical MS components.

In the present study, there was a predominance of anxiety symptoms of severe intensity, measured by HARS. A similar result was obtained by Caroll et al. (2009), in a sample of 4256 patients in which the Generalized Anxiety Disorder is positively associated with MS. However, they did not observe the association between MS and serious depressive symptoms.

In our study, we obtained higher intensity of anxiety symptoms among the women than among the men who composed our sample. According to Räikkönnen, Mattews \& Kuller (2002) healthy women with symptoms of anxiety and depression had a higher incidence of metabolic syndrome after 7.4 years after the first evaluation of their psychological condition. It was observed, however, that women who already had a diagnosis of MS, presented after the same 7.4 years a significant increase in the intensity of symptoms of anxiety and hostility, concluding that the association between psychological conditions and MS goes both ways.

In the study proposed by Wottrich et al. (2011) there is predominance of stress in women $(41.4 \%$ of women and $15.5 \%$ of men) in the near-exhaustion phase.

The positive association between females and anxiety symptoms is consistent with results from other studies showing high prevalence of anxiety disorders in this population, influenced by the condition of women in society and their duties, and also influenced by hormonal changes (Kinrys \& Wygant, 2005).

It was also found that the educational level was inversely related to the intensity of anxiety symptoms, corroborating the findings of other studies such as that conducted by researchers Maragno, Goldbaum, Gianini, Novaes and César (2006) in the, Programa de Saúde da Familia (PSF, Family Health Program of Brazil).This same finding has led to the hypothesis that this data can be affected by stressors related to unfavorable socioeconomic conditions (Maragno et al., 2006).
However, the association between anxiety symptoms and MS is not clearly defined. In part, this association may be related to the perception of cardiovascular risk that the patient may have after the diagnosis of MS. Moreover, it is possible that neurovegetative symptoms present in anxious states, including fatigue, represents the potentiation of the positive association between depressive symptoms and MS, as states of anxiety and depression share symptoms such as irritability and complaints of somatic order, which can be reported by patients before the symptoms of depressed mood itself in the context of primary care.

Patients who experience severe anxiety symptoms may also adopt risk behaviors to health care such as changes in sleep patterns, excessive food intake and alcohol abuse in trying to get reassurance, which may contribute to changes in cardiovascular and metabolic parameters compromising the control of clinical variables of MS. Furthermore, high levels of anxiety can lead to poorer quality of life.

The data obtained by Lipp, Pereira, Justo and Matos (2006) show that, in a sample with mild hypertension, psychological variables, among which emotional stress, are important factors in determining the magnitude of the cardiovascular response. In turn, Tully, Baker and Knight (2008) reported that anxiety symptoms, and not depression, are associated with mortality after coronary artery bypass grafting. According to Keltikangas-Järvinen, Räikkönen, Hautanen and Adlercreutz (1996) chronic fatigue and psychological variables such as stress and hostility, correlate significantly with hyperglycemia, hypertension and central obesity, the latter clinical variables of MS.

Through the present study, it could be concluded that there was a predominance of anxiety symptoms of severe intensity, especially in women, and among those with low educational level. Further studies on the role of anxiety symptoms in MS must be performed.

\section{References}

Arenas, M. D., Álvarez-Ude F., Reig-Ferrer A., Zito J.P., Gil, M. T., Carretón, M. A., et al. (2007). Emotional distress and healthrelated quality of life in patients on hemodialysis: The clinical value of COOP-WONCA charts. Journal of Nefhrology, 20(3), 304-310. 
Björntorp, P. (2001). Do stress reactions cause abdominal obesities and comorbidities? Obesity Reviews, 2(2), 73-86.

Blumenthal, J. A., Lett H. S., Babyak M. A., White W., Smith P. K., Mark D. B., et al. (2003). Depression as a risk factor for mortality after coronary artery bypass surgery. The Lancet, 362(9384), 604-609.

Capuron, L., Shaoyong S., Miller A. H., \& Bremner J. D. (2008). Depressive symptoms and metabolic syndrome: Is inflammation the underlying link? Biological Psychiatry, 64(10), 896-900

Carroll, D, Phillips A. C., Thomas G. N., Gale C. R., Deary I., \& Batty G. D. (2009). Generalized anxiety disorder is associated with metabolic syndrome in the Vietnam experience. Biological Psychiatry, 66(1), 91-93.

Corella, D., \& Ordovas J. M. (2004).The metabolic syndrome: A crossroad for genotype-phenotype associations in atherosclerosis. Current Atherosclerosis Reports, 6(3), 186-196.

Cunha, J. A. (2001). Manual da versão em português das Escalas de Beck. São Paulo: Casa do Psicólogo.

Diaz-Martínez, L., Serrano N., Pinzón J., Mantilla G., Velasco H., Martínez L., et al. (2007). Lack of association between metabolic syndrome and depressive symptoms in Colombian adults. Revista Médica de Chile, 135(8), 990-996.

DiMatteo, M. R., Lepper, H. S., \& Croghan, T. W. (2000). Depression is a risk factor for noncompliance with medical treatment: Meta-analysis of the effects of the anxiety and depression on patient adherence. Archives of International Medicine, 160(14), 2101-2107.

Ford, E. S., Giles W. H., \& Dietz W. H. (2002). Prevalence of the metabolic syndrome among US adults: Findings from the third national health and nutrition examination survey. JAMA, 287(3), 356-9.

Grigsby, A. B., Anderson, R. J., Freedland, K. E., Clouse, R. E., \& Lustman, P. J. (2002). Prevalence of anxiety in adults with diabetes: A systematic review. Journal of Psychosomatic Research, 53(6),1053-1060.

Grundy, S. M., Cleeman J. I., Daniels S. R., Donato K. A., Eckel R. H., Franklin B. A., et al. (2005). Diagnosis and management of the metabolic syndrome: An American Heart Association/National heart, lung and blood Institute Scientific Statement. Circulation, 112(17), 2735-2752.

Hamilton, M. (1959). The assessment of anxiety states by rating. British Journal of Medical Psychology, 32(1), 50-55.

Herva, A., Räsänen, P., Miettunen, J., Timonen, M., Läksy, K., Veijola, J., et al. (2006). Co-ocuurrence of metabolic syndrome with depression and anxiety in young adults: The Northern Finland 1966 Birth Cohort Study. Psychosomatic Medicine, 68(2), 213-216.

Huffman, J. C., Smith, F. A., Blais, M. A., Januzzi, J. L., \& Fricchione, G. L. (2008). Anxiety, independent of depressive symptoms, is associated with in-hospital cardiac complications after acute myocardial infarction. Journal of Psychosomatic Research, 65(6),557-63.

Keltikangas-Järvinen, L., Räikkönen, K., Hautanen, A., \& Adlercreutz, H. (1996). Vital exhaustion, anger expression, and pituitary and adrenocortical hormones implications for the insulin resistance syndrome. Arteriosclerosis Thrombosis Vascular Biology, 16(2), 275-28.
Kinder, L. S., Carnethon, M. R., Palaniappan, L., King, A., \& Fortmann, S. P. (2004). Depression and the metabolic syndrome in young adults: Findings from the third national health and nutition examinationg survey. Psychosomatic Medicini, 66(3),316-322.

Kinrys, G., \&Wygant, L. E. (2005). Anxiety disorders in women: Does gender matter to treatment? Revista Brasileira de Psiquiatria, 27(Suppl.2), 43-50.

Koponen, H., Jokelainnen, J., Keinänen-Kiukaanniemi, S., Kumpusalo, E., \& Vanhala, M. (2007). Metabolic syndrome predisposes to depressive symptoms: A population-based 7-year follow-up study. The Journal Clinical Psychiatry, 69(2): 178-182.

Lipp, M. E. N., Pereira, M. M. B., Justo, A. P., \& Matos, T. M. G. (2006). Cardiovascular reactivity in hypertensives: Differential effect of expressing and inhibiting emotions during moments of interpersonal stress. Spanish Journal of Psychology, 9(2). Retrieved May 4, 2007, from <http:// www.ucm.es/info/Psi/docs/journal/v9_n2_2006// art154.pdf>.

Maragno, L., Goldbaum M., Gianini, R. J., Novaes, H. M. D., \& César, C. L. G. (2006). Prevalence of common mental disorders in a population covered by the Family Health Program (QUALIS) in São Paulo, Brazil. Cadernos de Saúde Pública, 22(8), 1639-1648. Retrieved October 18, 2013, from <http://www.scielosp.org > doi: 10.1590/S0102-31 1X2006000800012

National Cholesterol Education Program. (2001). Expert panel on detection, evaluation and treatment of high blood cholesterol in adults. JAMA, 285(19), 2486-2497.

Räikkönnen, K., Mattews, K. A., \& Kuller, L. H. (2002). The relationship between psychological risk attributes and the metabolic syndrome in healthy women: Antecedent or consequence? Metabolism, 51(12), 1573-1577.

Skilton, M. R., Moulin P. P., \& Terra, J. L. (2007). Association between anxiety, depression, and metabolic syndrome. Biological Psychiatry, 62(11), 1251-1257.

Sociedade Brasileira de Hipertensão, (2004). I Diretriz brasileira de diagnóstico e tratamento da síndrome metabólica. Hipertensão, 7(4), 124-159.

Tully, P. J., Baker, R. A., \& Knight, J. L. (2008). Anxiety and depression as a risk factor for mortality after coronary bypass surgery. Journal of Psychosomatic Research, 64(3), 285-90.

Vaccarino, V., McClure C., Johnson D., Sheps D. S., Bittner V., Rutledge T., et al. (2008). Depression, metabolic syndrome and cardiovascular disease. Psychosomatic Medicine, 70(1), 40-48.

Van Praag, H. M. (2005). Can stress cause depression? The World Journal Biological Psychiatry, 6(Suppl.2), 5-22.

Wottrich, S. H., Ávila C. M., Machado S. G., Dillenburg D., Kuhl C. P., Irigoyen M. C., et al. (2011). Gênero e manifestação de stress em hipertensos. Estudos de Psicologia (Campinas), 28(1), 27-34. doi: 10.1590/S0103-166×2011 000100003

Received on: 8/9/2011

Final version on: 27/2/2012

Approved on: 12/3/2012 